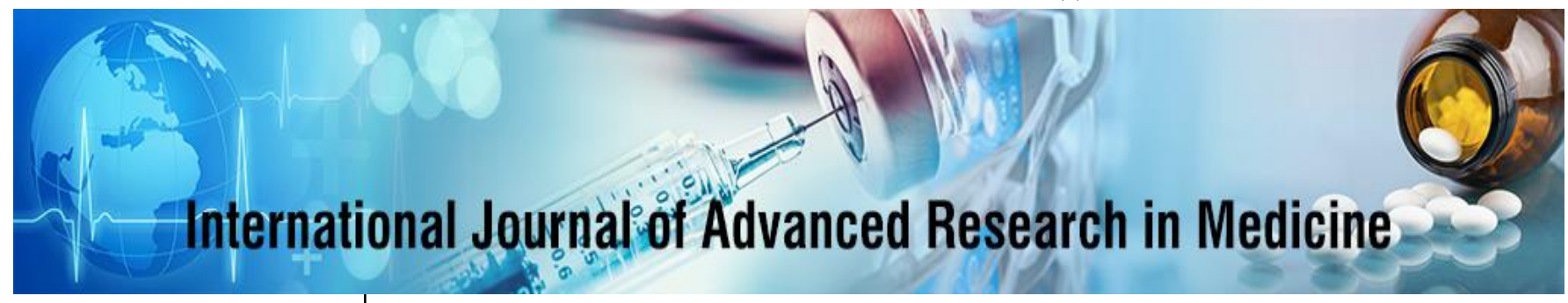

E-ISSN: 2706-9575

P-ISSN: 2706-9567

www.medicinepaper.net/

IJARM 2019; 1(2): 07-09

Received: 07-05-2019

Accepted: 09-06-2019

Dr. Siddhartha Shukla Department of medicine, Sri Balaji Action Medical Institute, Delhi, India
Corresponding Author: Dr. Siddhartha Shukla Department of medicine, Sri Balaji Action Medical Institute, Delhi, India

\section{Assessment of serum potassium levels in acute myocardial infarction patients}

\author{
Dr. Siddhartha Shukla \\ DOI: https://doi.org/10.22271/27069567.2019.v1.i2a.7
}

\begin{abstract}
Background: Myocardial infarction (MI) is one of the five main manifestations of coronary heart disease, namely stable angina pectoris, unstable angina pectoris, MI, heart failure and sudden death.

Potassium (K) is an intracellular ion, while the lower extracellular $\mathrm{K}$ levels are mainly regulated by renal excretion and exchanges between the intracellular and extracellular space. Hence; we planned the present study to assess serum potassium levels in acute myocardial infarction (AMI) patients.

Materials \& methods: A total of 10 AMI patients and 10 healthy controls were included in the present study. Detailed demographic and clinical data of all the subjects was obtained. Fresh blood samples were obtained from all the subjects and were sent to the laboratory for assessment. Serum potassium levels were analyzed by using an auto-analyzer. All the results were recorded in Microsoft excel sheet and were analyzed by SPSS software.

Results: Mean serum potassium levels among subjects of the AMI group and the control group was 4.12 and $4.62 \mathrm{mmol} / \mathrm{L}$ respectively. Significant results were obtained while comparing the mean potassium level among subjects of the AMI group and control group respectively.

Conclusion: AMI patients are significantly associated alteration in serum potassium levels, thereby, indicating the role of potassium in the pathogenesis of the disease.
\end{abstract}

Keywords: Myocardial infarction, potassium

\section{Introduction}

Cardiovascular disease is a global public health problem contributing to $30 \%$ of global mortality and $10 \%$ of the global disease burden. In 2005, from a total of 58 million deaths worldwide, 17 million were due to cardiovascular disease and, among them 7.6 million were due to coronary heart disease. Myocardial infarction (MI) is one of the five main manifestations of coronary heart disease, namely stable angina pectoris, unstable angina pectoris, MI, heart failure and sudden death ${ }^{[1-3]}$.

Potassium $(\mathrm{K})$ is an intracellular ion, while the lower extracellular K levels are mainly regulated by renal excretion and exchanges between the intracellular and extracellular space. Extracellular $\mathrm{K}$ and its shifts can modify the electrophysiological properties of the resting membrane potential in myocardial cells and influence the generation and conduction of impulses in the heart ${ }^{[3,4]}$. Several studies have demonstrated a relationship between low serum potassium levels, usually less than $3.5 \mathrm{mEq} / \mathrm{L}$, and the risk of ventricular arrhythmias in patients with acute myocardial infarction (AMI) ${ }^{[1-7]}$. On the basis of these studies, experts and professional societies have recommended maintaining potassium levels between 4.0 and $5.0 \mathrm{mEq} / \mathrm{L}, 8,9$ or even 4.5 to $5.5 \mathrm{mEq} / \mathrm{L}, 10$ in AMI patients ${ }^{[5-7]}$.

Hence; under the light of above obtained results, we planned the present study to assess serum potassium levels in acute myocardial infarction (AMI) patients.

\section{Materials \& methods}

The present study was conducted with the aim of assessing serum potassium levels in AMI patients. A total of 10 AMI patients and 10 healthy controls were included in the present study. Inclusion criteria for the present study included:

- Patients within the age group of 20 to 60 years,

- Patients with negative history of any other systemic illness,

- Patients with negative history of any known drug allergy 
Detailed demographic and clinical data of all the subjects was obtained. Fresh blood samples were obtained from all the subjects and were sent to the laboratory for assessment. Serum potassium levels were analyzed by using an autoanalyzer.

All the results were recorded in Microsoft excel sheet and were analyzed by SPSS software. Chi-square test was used for assessment of level of significance.

\section{Results}

In the present study, assessment of a total of 10 AMI patients and 10 healthy controls was done. Mean age of the patients of the AMI group was 42.8 years. Mean age of the patients of the control group was 43.1 years. There were 6 males and 7 males in the AMI group and control group respectively. Mean BMI of the patients of the AMI group was $26.2 \mathrm{Kg} / \mathrm{m}^{2}$ while mean BMI of the patients of the control group was $26.4 \mathrm{Kg} / \mathrm{m}^{2}$ respectively. Mean serum potassium levels among subjects of the AMI group and the control group was 4.12 and $4.62 \mathrm{mmol} / \mathrm{L}$ respectively. Significant results were obtained while comparing the mean potassium level among subjects of the AMI group and control group respectively. Prevalence of hypokalemia among patients of the AMI group was 60 percent.

\section{Discussion}

Acute myocardial infarction occurs when there is an abnormal ischemic alteration of the myocardium due to an inability of the coronary perfusion to meet the myocardial contractile demand. The possible mechanism for the low concentrations of sodium and potassium in AMI is the impairment of the $\mathrm{Na} / \mathrm{K}$ pump and the $\mathrm{Na} / \mathrm{Ca}$ exchanger. The active transport of these ions across cell membrane involves ATPase, which in turn is dependent on $\mathrm{Mg}$ for its activity ${ }^{[7-9]}$.

Hypo- and hyperkalemia have been shown to increase cardiovascular and total mortality in patients with acute myocardial infarction (AMI). Hypokalemia refers to a serum potassium concentration (SPC) of $<3.5 \mathrm{mEq} / \mathrm{l}$, occurs frequently in hospitalized patients and is associated with ventricular arrhythmias as well as an overall poor prognosis after cardiovascular events. Hyperkalemia is defined as a SPC of $>5.0 \mathrm{mEq} / \mathrm{l}$ and can have a variety of adverse consequences, such as cardiac arrhythmias, in patients hospitalized after a cardiovascular event. In patients with AMI recommended SPC are between 4.0 and $5.0 \mathrm{mEq} / 1$ or above $4.5 \mathrm{mEq} / \mathrm{l}^{[10-12]}$.

In the present study, assessment of a total of 10 AMI patients and 10 healthy controls was done. Mean age of the patients of the AMI group was 42.8 years. Mean age of the patients of the control group was 43.1 years. There were 6 males and 7 males in the AMI group and control group respectively. Mean BMI of the patients of the AMI group was $26.2 \mathrm{Kg} / \mathrm{m}^{2}$ while mean BMI of the patients of the control group was $26.4 \mathrm{Kg} / \mathrm{m}^{2}$ respectively. Mean serum potassium levels among subjects of the AMI group and the control group was 4.12 and $4.62 \mathrm{mmol} / \mathrm{L}$ respectively. Kafka $\mathrm{H}$ et al. assessed the serum magnesium and potassium in acute myocardial infarction. Over a 13-month period, serum potassium and magnesium levels were measured in 590 patients admitted to a coronary care unit. Hypokalemia, often in the absence of diuretic use, occurred in $17 \%$ of the 211 patients with acute myocardial infarction. Patients with acute myocardial infarction and a potassium level of less than $4.0 \mathrm{mEq} / \mathrm{L}(4.0 \mathrm{mmol} / \mathrm{L})$ had an increased risk of ventricular arrhythmias (59\% vs $42 \%)$. Because hypokalemia is common in acute myocardial infarction and is associated with ventricular arrhythmias, routine measurement of serum potassium levels and prompt correction are recommended. Hypomagnesemia occurred in only $4 \%$ of the patients, but it was more common in the group with acute myocardial infarction than in the group without myocardial infarction (6\% vs 3\%). Ventricular arrhythmias occurred in ten of the 13 patients with both acute myocardial infarction and hypomagnesemia, but eight of these patients also had low serum potassium levels. This low incidence of hypomagnesemia does not justify routine measurement of serum magnesium levels. However, the mean level $(2.5+/-0.4 \mathrm{mg} / \mathrm{dL}$ [1.03 +/- $0.16 \mathrm{mmol} / \mathrm{L}])$ in a reference population of healthy volunteers was unexpectedly high and suggests that the low incidence of hypomagnesemia in their population may not be applicable to other centers and may reflect a higher magnesium content in their geographic area of southeastern Ontario ${ }^{[11]}$.

In the present study, significant results were obtained while comparing the mean potassium level among subjects of the AMI group and control group respectively. Prevalence of hypokalemia among patients of the AMI group was 60 percent. Colombo MG et al. examined the association between SPC and long-term mortality following AMI in patients recruited from a population-based registry. Included in the study were 3347 patients with AMI aged 28-74 years consecutively hospitalized between 1 January 2000 and 31 December 2008 and followed up until 31 December 2011. Patients were categorized into five serum potassium concentration (SPC) groups $(<3.5,3.5$ to $<4.0,4.0$ to $<4.5$, 4.5 to $<5.0$, and $\geq 5.0 \mathrm{mEq} / \mathrm{l}$ ). The outcome of the study was all-cause mortality. 249 patients $(7.4 \%)$ had a low SPC $(<3.5 \mathrm{mEq} / \mathrm{l})$ and $134(4.0 \%)$ patients had a high SPC $(\geq 5.0$ $\mathrm{mEq} / \mathrm{l})$. Patients with SPC of $\geq 5.0 \mathrm{mEq} / 1 \mathrm{had}$ the highest long-term mortality (29.9\%) and in the adjusted model, their risk of dying was significantly increased (HR 1.46, 95\% CI 1.03 to 2.07) compared to patients with SPC between 4.0 and $<4.5 \mathrm{mEq} / \mathrm{l}$. Analyses of increasing observation periods showed a trend towards a higher risk of dying in patients with SPC between 4.5 and $<5.0 \mathrm{mEq} / \mathrm{l}$. An admission SPC of $\geq 5.0 \mathrm{mEq} / 1$ might be associated with an increased mortality risk in patients with AMI ${ }^{[12]}$.

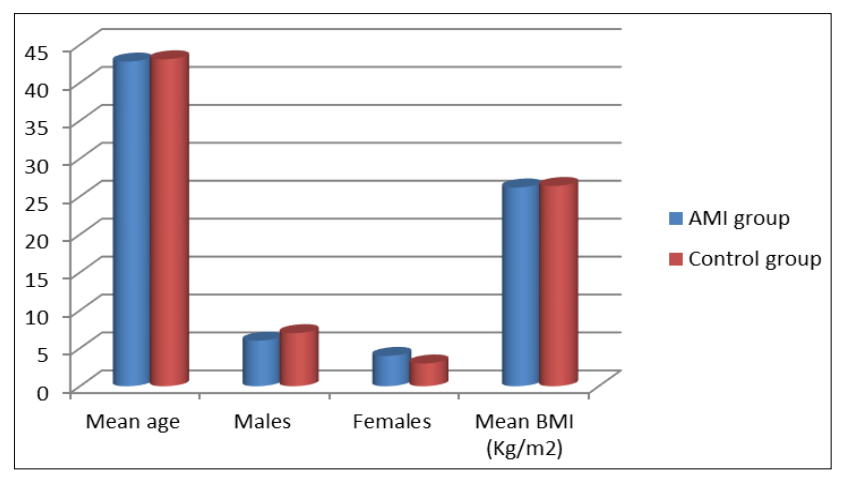

Graph 1: Demographic data

Table 1: Comparison of mean potassium levels among the two study groups

\begin{tabular}{|c|c|c|c|}
\hline Parameter & AMI group & Control group & p- value \\
\hline $\begin{array}{c}\text { Serum potassium } \\
\text { levels (mmol/L) }\end{array}$ & 4.12 & 4.62 & 0.02 \\
\hline
\end{tabular}


Table 2: Prevalence of hypokalemia among the subjects of the AMI group

\begin{tabular}{|c|c|c|}
\hline Parameter & Number of subjects & Percentage of subjects \\
\hline Hypokalemia & 6 & 60 \\
\hline
\end{tabular}

\section{Conclusion}

From the above results, the authors concluded that AMI patients are significantly associated alteration in serum potassium levels, thereby, indicating the role of potassium in the pathogenesis of the disease. However; further studies are recommended.

\section{References}

1. Xianghua F, Peng Q, Yanbo W, Shigiang L, Weize F, Yunfa J. The relationship between hypokalemia at the early stage of acute myocardial infarction and malignant ventricular arrhythmia. Heart. 2010; 96:196.

2. Tada Y, Nakamura T, Funayama H, Sugawara Y, Ako $\mathrm{J}$, Ishikawa SE et al. Early development of hyponatremia implicates short-and long-term outcomes in ST-elevation acute myocardial infarction. Circulation J. 2011; 75(8):1927-33.

3. Rogers WJ, Frederick PD, Stoehr E et al. Trends in presenting characteristics and hospital mortality among patients with ST elevation and non-ST elevation myocardial infarction in the National Registry of Myocardial Infarction from 1990 to 2006. Am Heart J. 2008; 156(6):1026-103419032996

4. Krogager ML, Eggers-Kaas L, Aasbjerg K, Mortensen RN, Kober L, Gislason G et al. Short-term mortality risk of serum potassium levels in acute heart failure following myocardial infarction. Eur Heart J CVP. 2015; 1:245-251.

5. Kast DL. Prevalence of hypokalaemia in acute myocardial infarction patients. Int J Contem Med Surg Radiol. 2018; 3(2):B41-B43.

6. Shiyovich A, Gilutz H, Plakht Y. Serum potassium levels and long-term post-discharge mortality in acute myocardial infarction. Int J Cardiol. 2014; 172:e368e370.

7. Colombo MG, Kirchberger I, Amann U et al. Admission serum potassium concentration and longterm mortality in patients with acute myocardial infarction: results from the MONICA/KORA myocardial infarction registry. BMC Cardiovasc Disord. 2017; 17(1):198. Published 2017 Jul 24. doi:10.1186/s12872-017-0635-X

8. Singla I, Zahid M, Good CB, Macioce A, Sonel AF. Effect of hyponatremia $(<135 \mathrm{mEq} / \mathrm{L})$ on outcome in patients with non-ST-elevation acute coronary syndrome. Am J Cardiol. 2007; 100(3):406-8.

9. Alizadehasl A, Sepasi F, Azarfarin R, Ghaffari S. Hypokalemia, arrhythmias and early outcomes in acute myocardial infarction. Res J Bio Sci. 2008; 3(9):11302.

10. Solomon RJ, Cole AG. Importance of potassium in patients with acute myocardial infarction. Acta Med Scand. 1981; 209(S647):87-93.

11. Kafka H, Langevin L, Armstrong PW. Serum magnesium and potassium in acute myocardial infarction. Influence on ventricular arrhythmias. Arch Intern Med. 1987; 147(3):465-9.

12. Colombo MG, Kirchberger I, Amann U, Heier M, Thilo $\mathrm{C}$, Kuch B et al. Admission serum potassium concentration and long-term mortality in patients with acute myocardial infarction: results from the Monica/Kora myocardial infarction registry. BMC Cardiovasc Disord. 2017; 17(1):198. Doi: 10.1186/s12872-017-0635-x. 